\title{
13 Notes on the contributors' experiences
}

\section{Insights into autoethnographic research}

\author{
Edgar Rodríguez-Dorans and \\ Jason Holmes
}

Reflexivity and writing are integrated into autoethnography as skills that allow researchers to make sense of their personal experiences at the intersection of social and cultural phenomena. The private nature of writing can make its process inaccessible and mystified. To offer an insight into this personal process, we wanted to provide the reader with notes that would address how it was to write this book. We wrote these notes based on the contributors' reflections on the writing process. Throughout the edition of the book, we invited the contributors to have a conversation with us via video conferences to better understand their engagement with the topics they wrote about and their methods of inquiry.

Some of them preferred to meet with us individually; some others took part in small group conversations. The objective of the meetings was to demystify the writing process and learn more about it by asking contributors to speak about the difficulties and concerns they faced and the times when it went with ease. We wanted to present readers with the process of finding personal space and voice and how authors might have solved potential struggles to find the message they wanted to distil and reflect on those times when they asked themselves, 'what is this about?' All authors were at different stages of the writing process; some were at the conceptualisation phase, where there are ideas, but there is nothing really on the page. Others had already provided the first draft, while some others had already completed their text. The different stages of writing reflected in their comments about what it was like to write autoethnographically.

These conversations had the purpose of exploring three key aspects: how they conceptualised 'the everyday' in their own chapters, which was especially important given the scarcity of research about ordinary aspects of gay life; we also explored ethical concerns during the writing and how they resolved them; and, finally, we were interested in aspects of craft, or in other words, how their writing looked in practice. While we had these themes as a guideline for the meetings, these were an organic engagement with the contributors. As we wrote in the introduction, we knew some authors beforehand, but in other cases, these online meetings were the first time that we had spoken to them. 
Perhaps these conversations spoke to our need - as editors - to know more about the contributors and to establish a personal connection with them. Since we were asking them to share with us aspects of life that had personal significance, we wanted to make sure that authors were 'comfortable' with the project. The word 'comfortable' proved to be a difficult one, as many of the writings exposed the 'relational ethics' Carolyn Ellis (2007) writes about, in which autoethnographers need to: 'act from our hearts and minds, acknowledge our interpersonal bonds to others, and take responsibility for actions and their consequences' (p. 3). Envisioning that some aspects of engaging with personal narrative could elicit some distress in contributors, we wanted to provide an outlet where they could express any concerns that they may have.

We knew this section was asking authors to access vulnerable parts of themselves outside of the written-based work. A conversation is 'immediate' and might not always offer the opportunity to leave the writing and come back to it to edit. In a conversation, one might express things differently than they would in writing. To create a sufficiently 'safe' space for these men to talk about what went on for them while writing their chapters, and for the right to process this material away from the anxiety of being named, in this section we withhold the contributors' identities.

Finally, we also wanted these live conversations to be an opportunity to bridge potential disciplinary and methodological divisions in what was a diverse group of writers. Thus, we conceptualised these conversations around reflexive practices, writing process, and support sessions to promote writers' involvement with their inquiry throughout the prewriting, during, and post-writing stages. We used Zoom recording capabilities to record the conversations with authors. We used ELAN to transcribe the audio-recordings and make sense of the discussions with contributors.

\section{Conceptualising and operationalising 'the everyday'}

Because 'the everyday' is highly personal, conceptualising it was a complex task for authors. Indeed, there were various ways the everyday was conceived in different chapters. One of these ways of understanding the everyday was through 'everyday memories'. For example, one author rooted his chapter in someone else's statement, a powerful phrase that had stayed in his memory. Others engaged with thoughts, images, happenings, or certain relationships that were constantly on their minds, and therefore, were an essential part of their identities. These kernel moments offered a powerful focus point that elicited the start of a 'self-search' process.

Some aspects of their writing came about as epiphanies, a moment in which they realised that what they saw as ordinary, perhaps was not ordinary for everyone. An author told us about how his idea for the chapter emerged when standing in a room, staring at a wall, thinking about the writing. He needed something event-driven that would pull out his emotions, something that added colour and texture to the writing. 
For other authors, the development of the chapter was strongly associated to a sense of place. For example, some authors talked about how being about to have a shower, or about to travel, or while doing chores - space where they do a lot of thinking - helped them engage with a profound sense of loss, insight, loneliness, love, and confusion that were later reflected in their chapters. One author expressed how the writing experience helped him realise he had not fully accepted his gayness and the realisation made him feel 'fresh and liberated'.

For several contributors, the papers they wrote for this book were part of larger projects and they used this opportunity to focus on the everyday as a novel angle. One author described:

'I've been working on theorising this topic for a couple years, and in this case, I used 'the ordinary' to think about intimacy. So this chapter will contribute to a larger exploration. I work out complex concepts in different venues. However, this one allows me to deep dive into the notion of intimacy from a personal and cultural perspective'.

\section{The need to write about a topic}

The idea that the topic finds the author and not vice versa is a discussion that has taken place in academic writing: for example, writing as a method of inquiry, autoethnography, poetic inquiry, and research as activism are some of the disciplines that have presented alternatives to research that resist prescriptive methodologies (see Gale and Wyatt, 2017; Wyatt, 2019; Richardson and St. Pierre, 2005; St. Pierre, 2017; Prendergast et al., 2009; Galvin and Prendergast, 2016). The notion that the topic finds the writing suggests that the theme of discussion is so pressing, momentous, and timely that it is almost 'inevitable' or 'necessary' to write about it. One author commented that the question of deciding on the topic of his chapter posed an ontological challenge for him, as he did not think he had had any agency in writing about it. He said:

Part of my experience was of this chapter coming to me, almost as if it was a life of its own, almost as if it needed to be written or it wanted to be written, which is very unusual for me. But that's what the experience was like. I'm not claiming any kind of belief in spirituality or anything like that, or in life outside of us - living creatures on this planet - but something quite remarkable happened in the construction of this chapter. In my experience of it ... I was clear from the beginning that I needed to write about it.

Similarly, other contributors were clear on what topic to write about from the beginning, which suggests a sense of certainty about their choices. Looking back at the abstracts they provided when the book was in its proposal stage, these confirmed a certain stability about the topics the author's wanted to address. They took their work in progress to retreats, on their travels, to their everyday spaces; they 'carried' their inquiries with them wherever they were - running in the hills, in their visits to home towns; and 
when abroad, at home and elsewhere, spending time by themselves thinking, working, writing, processing. They wrote notes and started writing and reading along with ideas of what it means to be gay. They 'wrote and wrote and wrote'. Because they had this inner certainty about what they needed to write about, the chapters came about with a sense of promptness. One author expresses that the chapter 'wrote itself', to convey it flowed really quickly. It was the same for another writer who said he was not worried about things to write, he just needed to find the time to write them.

As an explanation to the notion that they developed their chapters as an inner need or urgency to write them, one contributor explained he saw in his chapter the opportunity to ask questions that others like him may struggle to ask. His aim was to give tools and resources to those traumatised by abandonment, exclusion, and ostracisation. This experience was like other contributors' narratives of engaging with their own chapters in which their writing was responding to a stimulus that came from a deep and continuous immersion in their experiences and the contexts in which they inhabited. Their writing would reveal to them the extent to which they felt their need was not only a personal quest for meaning, but it was also a call to interrogate certain aspects of their lives that at first glance could be considered 'ordinary', but upon reflection, they revealed problematic dynamics, inequalities, and broader issues rooted in the social and cultural milieus they inhabit.

\section{The symbolic presence of community in the writing}

The importance of a community of gay men - real or symbolic - was a crucial theme in the authors' writings. The idea of 'community' was complex, and it differed between authors, but in all cases, it was expressed as essential because it represented connection in four major aspects: to learn about gayness, to feel at ease and write freely, to feel understood, and to mentor other gay men. Authors expressed how having a sense of a gay community during their process of inquiry helped them to engage in discussions that otherwise would be difficult to address.

One expressed they had an imaginary LGBTQIA+ audience in mind, and they intentionally 'wrote for them' and for queer people whose voices have been lost. They worried their writing may be 'too much', perhaps 'too queer', but if they didn't express it, if they 'didn't tell their truth, it was never going to get out there'. They are part of a culture that is expressive, yet queer people in that culture are not expressive of their emotions and feelings. They wanted to pave a way so other queer people like them can speak about themselves, because in doing so, more queer connections may occur.

As the contributor said:

I want people in the queer community back home to read this stuff, a piece from my fairly unknown hometown, and realise: 'Oh my god! This exists!' It fills me with inspiration. I haven’t met anyone from my hometown 
telling this type of story. The exposure would be great not only for me, but others like me that have these stories, but didn't think their stories mattered.

For this contributor, writing was an act of advocacy. They really wanted something - loss of family, loss of community and rejection - that could connect with others in LGBTQIA+ communities. They felt their motivation, but also that they wanted their writing to be raw and emotional. They sought to write about experiences that no one spoke about. Growing up, they felt everyone was closed and didn't express their truths, so they sought to do the complete opposite. They wanted to be a representative of their culture and share their heart and mind with the world.

Other authors reported their work with gay men extends beyond this book and is an integral part of their professional lives. Reflecting on this work, one narrated: 'Why do I work with gay men? It is about motivation and personal commitment to contribute to a community to which I feel I belong.' He wanted this to be reflected in his chapter. So, as part of his writing process, he wrote about this motivation. He continues: 'And tracing that back to discovering being gay in the first place and then almost telling a life story of discovering right up to today and working in this field.' This continuous reflective process helped him realise he wanted to write about his work itself and more about what it means to belong to a community or to have a sense of belonging to a community.

\section{Ethics and unexpected issues in writing these autoethnographies}

As researchers, mental health practitioners, and gay men ourselves, we (Edgar and Jason) were aware of the caveats of editing a collection of texts that would deal with intimate aspects of everyday life, potentially sexual themes, and mental health issues. We were conscious of various ethical deliberations to which we would be exposed. Accordingly, we aimed to base our decisions and actions on ethical values, decision-making models, and ethics codes. Equally important, we were in continuous reflection and discussion between us as editors about potentially difficult content. Collecting these autoethnographic stories resembled the research process of working with participants in a research study. We understood contributors are familiar with academic practices when conducting research, and some of them deal with ethical concerns regularly, so they would be conscious of managing difficult disclosures.

However, we also knew that most contributors would not have the privilege of anonymity to protect them from painful revelations. Autoethnography is an approach to research in which ethics take an unexpected turn: researchers are well-trained in the ethics that take care of participants, but taking care of the self can be a more sinuous trail. Having your name attached to a text that can put you in a precarious position is a decision that requires an ongoing assessment. In one instance, we talked with one contributor about 


\section{Edgar Rodríguez-Dorans and Jason Holmes}

how his concerns about his chapter were conveying a sense of vulnerability that was making us feel worried. This was a process that we observed throughout the course of two years and led the three of us - editors and contributor - to finally agree that it was in his best interest to not take part in the collection. Although we believe it would have been an important contribution to this book and those who read it, the value of non-maleficence and the question 'how does writing this chapter benefit the contributor?' helped us decide that the concerns outweighed the benefits.

We want to clarify that this decision was not associated with the topic of the chapter; it was the contributor's response to the topic that guided our decision. This means that there were not 'untouchable' topics, but there were personal responses that made specific vulnerabilities emerge. Throughout the book there are diverse themes writers address and, while some of them might be upsetting to read, we always tried to ensure that writers took a reflective stance with their chapters - for example, throughout the period in which writers developed their chapters, we conversed with them over email and video calls at various points and asked whether they felt certain about the contents and disclosures in their respective texts. We wanted to ensure they were conscious and felt supported in the decisions they made within their writing.

These ongoing conversations with authors led us to categorise the ethical concerns into three main groups: (1) inclusion of other people's narratives into the author's writing; (2) concerning disclosures; and (3) contributors' wellbeing. These domains contemplated concrete questions we needed to consider as part of the publication process.

\section{Affective responses to the autoethnographic process}

This section highlights how the stories that authors shared in this book sometimes elicited a difficult process and how they managed those unexpected affective responses. The writing became an opportunity to foster selfunderstanding, and, most times, participants came out of them with a sense of being transformed, with a different understanding of who they were. One autoethnographer shared how, in the prewriting process, he dealt with ideas and experiences that he needed to process before he could express them publicly. Some feelings were still raw, some experiences were still confusing, and he needed to understand his feelings for those experiences before he could say something about them.

Another contributor described uncomfortable emotional states that he experienced during the writing. As he is a theatre artist, he described how writing is an opportunity to do similar emotional work to when he creates a character. Yes, he experienced anxious states during the writing, but he narrated how, as an actor, he has learnt that that can be the premise that underlies his artistry and his craft, and he could apply for that work in performance to his autoethnographic research. 
For one autoethnographer, writing this piece brought him into really 'dark places'. He narrated how he wrote and left the text for some time, then went back, looked at it, and 'stayed with it'. He was not sure whether that was a 'healthy practice', but he recognised that the act of re-reading his writing had a desensitising component that helped him cope with the difficult content. He continued: '[My writing] will go into very dark spaces. If it's too tricky a space, either I will stay there or quit, I come back to it later, find another way to say it. Or I just won't go there'.

Some contributors felt apprehensive about writing about their gayness. One was disclosing his gay identity in writing for the first time and revealed that this raised significant boundary issues and dilemmas about disclosure that were not straightforward to address. He said: 'If you'd asked me last year or the year before (our invitation to contribute), my answer would have been "no". This piece of work is highly revealing'. His dilemma evoked a period of reflection. Talking about different issues, sometimes having dialogues with himself, conversations with others, posing questions about boundaries and imaginary scenarios of 'how much should I reveal?' These considerations, which responded to ethics of selfcare, were the most difficult part of the process, more than the writing itself.

He was not alone in reporting that once early hesitations or decisions had been resolved, a quick flowing process ensued. Three other contributors spoke about writing a rough draft - 'a vomit', 'an expulsion of information' very quickly. These early drafts were just for their personal use, only to see where the writing process took them. They 'slept on these drafts', maybe only working on them two days a week, sometimes the writing was considered terrible (e.g., 'I can't believe I said that') and led to changes in structure or voice.

\section{Over-exposure}

Historically, gay men's lives have been open to scrutiny. This has generated what Frederick (2014) calls 'gay discontent'. He writes: '[Men who have sex with men] - and more recently "gay" men-have been stigmatised by the oppressive and marginalizing policies of numerous systems of social control (criminal law, canon [church] law, medicine, public health, behavioral sciences, etc.)' (p. 141). As editors, we were concerned that this book could, inadvertently, expose the narratives of contributors to forms of scrutiny that could reproduce these harmful practices of control of policing. Throughout the course of the edition of manuscripts, we were aware that a book that uses autoethnography as its method will always have an element of vulnerability that comes from self-exposure. With this in mind, we had the principles of non-maleficence and benefit as our guideline to make sure that the writings presented here did not come at the detriment of the contributors' wellbeing. 


\section{Edgar Rodríguez-Dorans and Jason Holmes}

One writer, whose text focused on sexuality and eroticism in digital platforms, asked at various points of the process 'how revealing' he needed to be in his disclosures. We explored the reasons he felt the need to be 'revealing'. These conversations brought about topics of the exoticisation and marginalisation of gay men's relationships that have permeated into mainstream idiosyncrasies. It became apparent how the contributor was comfortable discussing these topics of gay eroticism in the safety of the conversations with editors, but he realised it was something that he did not want to share with the readers. He decided he would not share that aspect of life at this point.

Other authors also expressed similar views about how gay men's lives have been poorly studied in the sense that research on gay men's lives is scarce, and the studies that exist have centred primarily on gay men's sexualities. This brought about whether they would want to contribute to that sex-centred discourse. One way in which contributors reached a compromise with themselves was by emphasising that the parts of their writing that centred on sex are told in their own terms and by remembering that the book was a space that offered an opportunity for other gay men to read about content that applies to their own lives.

One author expressed how this opportunity was profoundly important because, throughout his life, he had already been working on lots of boundary issues regarding: 'What am I prepared to say about myself? I come from a culture where it was almost impossible to be gay, through the 1970s and 80 s, and the idea of being open and disclosing especially in publication has always been there for me, and now it was time to take that opportunity'.

While the above account suggests the positive impact of disclosing aspects of their lives, we were mindful that some contributors were in a fragile or precarious position. One was anxious about the readership of the book and felt unprepared for the exposure it would offer. He expressed concerns about writing about certain parts of his intimate life and made a conscious decision not to address those issues in the light of negative consequences he could face in the geographical context he lives in. He expanded on this and spoke of wanting to protect his current relationship from public scrutiny. He has made past relationships open; he has even written for different platforms. Now, he does not want to write about his relationships, because he knows what he has done to himself in the past. He said:

'I have the power to do something different, to own my sexuality, my pleasures, and try different things. I don't regret writing about them in the past, it was fine, I liked it. But now, I know things I didn't know before, and I want to value that. Is not a question of being brave, but more a question of "it's my right not to disclose about my sexual life",

To understand how autoethnographers negotiate difficult disclosures in their writing, we asked them: 'How do you decide what to include and what is just for you?' They shared how, for some difficult content, it becomes a desensitising process. One of them discussed how autoethnography brings 
about: 'very uncomfortable writing that has caused me concerns, especially when using "I" as the main voice. Writing about serious mental health issues for the first time sucked, but it happened. I puked what I knew. I wrote around the situation. I don't like it; I'm going to flip it at you. Keep working on it, until I think: "great, I think it matters, and I want to include my story here". I could write it without the serious mental health issues, but I think that, out of honesty and commitment to readers, I want to be a bit more vulnerable'.

The theme of over-exposure revealed that the autoethnographic writing process was an ongoing negotiation with the self and others to decide what needed to be written and what would be detrimental to their own welfare.

\section{Writing in a pandemic}

As stated in the introductory chapter, some parts of this book were written during the COVID-19 pandemic. During this time, the lives of many took an unusual domestic focus, and the ordinary was highlighted. The 'everyday' angle of this book had been planned in pre-pandemic times, but the series of lockdowns, travel restrictions, and social distancing measures that took place around the world made the ordinary more evident for contributors.

For one of them, the pandemic created the 'occasion', a 'horrible, painful time' that is constantly traumatic about which he writes in his chapter. $\mathrm{He}$ said:

'We are experiencing multiple pandemics in which [we] are situated differently. People experience them differently because our privileges and disadvantages made some more vulnerable than others. And we are in the intersections of those multiple pandemics; even though we are not necessarily impacted by them in the same way, we are in the middle of them'.

During this horror, one contributor said he was forced everyday to look inwards for resources to get through it. The relationship he writes about has been his lifeline, and it has given him the faith and strength to look inside his own emotionality in these multiple pandemics and to sit in his place. Without the pandemic, he would have been distracted.

For another contributor, enforced solitude of his pandemic afforded him the time and space to sit with his piece long enough to decide it was ready to be read. He found writing during the pandemic a much-needed distraction that allowed him to get something moving and motivating and that took him away from the current situation.

It was the same for another contributor who saw the writing as a productive exercise in stepping outside this pandemic time. For him the pandemic was an everyday personal and ecological trauma, and he sought ways to deal with the grief that different people are being treated differently in what is a renewed time of violence. 


\section{Aspects of 'craft' in autoethnographic research: Autoethnography as a method}

In response to the question: 'What do you think autoethnography does as a method that other methods don't or can't?' One contributor responded that it's a method that 'draws out the human soul [...] it's almost magical'. For him, autoethnography pulls out understanding from experience and connects it to the broader human shared experience. He finds it elusive, like looking in a mirror: 'Sometimes you are comfortable with what you are looking at, others you are not'. He continued:

'Autoethnography is flexible, but it's also a hard truth. It's a very careful process; you have to check in with your emotions and reflections. Feeling okay to write about the contents of this chapter was a process that took years. Before now, my capability to write about that experience was limited.'

Another author coincided with the notion of autoethnography being a flexible but hard method. He believes autoethnography benefits from disclosing aspects of relationships that are only accessible to the self, and although he really wanted to do that, he felt he could not do that completely, as he is in a relationship with someone who is really private. His writing became risky.

As editors, the tension between making private aspects of relationships public became a battle of forces in which our primary concern was the mental and professional wellbeing of the contributors. During the writing process, our ongoing relationship with them and the private conversations therein could manage this tension. However, we knew once the book was published, our ability to do so became limited. On this basis, and given that some were new to publishing autobiographical material, our dialogue with contributors on what aspects of relationships they were comfortable disclosing represented an important part of our relationships with these men. One author who was new to autoethnography narrated:

'I used a lot of personal experience in processing and managing my academic work, but I've not done autoethnographic work. This is the first time that I've written for an autoethnographic collection. However, I wouldn't say that it's hugely different from past work that I've done that has been published in other contexts. It's very, very personal, but it wasn't framed as autoethnographic'.

Some authors reflected on the scope, limits, and defining qualities of autoethnography. There seemed to be a consensus that what makes these texts autoethnographic is that they are all about the contributors' experiences and they are honest and open texts about culture - the culture that they come from, the culture that they live in, and the culture of their own disciplines.

\section{Sources to aid autoethnographic writing}

One contributor described how he always approaches his autoethnographic work by situating his own life, body, and experiences in the research. For him, 
that is the lens through which he can understand others. Autoethnography is a deeply personal process that requires a level of vulnerability, an evolving process that as a writer allows him to get closer to this representation of his own interiority and understand how this interiority can reflect or be useful to others.

Some contributors played with sources early in their writing process; others did so retrospectively once their autobiographical material had been generated. After writing their autobiographical material, some contributors were left with thinking about how they brought in broader cultural concepts and narratives and, as one contributor put it: 'the LGBTQ stuff'. In other words, there was an intentional and conscientious use of resources that were seen as potentially aiding the writing.

For one contributor, one of their main sources is 'a sister document', which they open in their computer and fill it with raw ideas. They often revisit that sister document and use it to find a focal point of their writing. Like many of the contributors, their focal point was a kernel scene, which served as an anchor where the writer could come back to - a focal point from where they could look at themes and 'connect with foreign ideas'. Once the focal point was established, the writing came together. As they said:

'Once I have an idea, other ideas come in rapidly. I wrote to see where these ideas were going, and, if I have a document where I can put them raw, then I can go through picking out these ideas'.

One contributor explored papers and online libraries seeing what material spoke to him. He used a filtering process in which he asked if the material helped to get his point across. In doing so, he concentrated on papers which explored human experience. He said: 'I am exploring myself and I connect to those [papers] more, which feel they are discussing real human experience'. For him, positivist papers didn't feel like 'real life'.

Other contributors knew they wanted to incorporate certain other works from the onset. These works were usually an area of long-term interest, such as certain theoretical concepts or an individual's body of work. They started the writing process with these works in mind. For these authors, the process was different from the free flow of autobiographical material about which the others spoke.

Sometimes the sources the authors used were acknowledged explicitly; sometimes they were more implicit. In these instances, their references to broader culture hung around their texts more subtly. These were things the contributors had read or assimilated throughout their lives. Put another way, the references are present in their writing but not so much they had them in mind; rather they are immersed in them, they are a part of them. Implicit acknowledgement of resources is illustrated for example in the following exchange between four of the contributors:

Contributor 1: 'It's what we do in life. I often talk about the book "The Velvet Rage" (Downs, 2006), it is part of my everyday'. 
Contributor 2: 'For me, it's Lorde (1984) when I think about desire and the erotic, I cannot help, but thinking about Lorde. I carry her with me. She opened my eyes to an important idea'.

Contributor 1: 'These books are part of us, and even if we don't quote or cite them directly when we talk about these issues, they are part of our embodied processes. We are thinking through the lens of the literature we have read'.

Contributor 2: 'Yes. I am not a Foucault expert, but his ideas have allowed me to write about the things I do. So, even though I am not using his theory or concepts for this piece, they are there. For example, I am sick of people saying monogamy is heteronormative. Why do you say that? Monogamy is not a straight privilege; anyone can be monogamous if they want. So it's something that sits perfectly with feminist thinking and queer theory and Foucauldian thinking and regulatory power, even though I am not quoting that in my discussions with people who criticise my relationship for being monogamous'.

The literature as a source was fundamental in autoethnographic writing. One author commented about his uncertainty about how open to be in his text, which led to him seeking reassurance from published articles where, as he said:

There are these guys talking openly about $[\ldots]$ the work and what happens in the work. And they offered me reassurance that we have to think about these delicate matters.

Reading what others had written gave contributors permission to write openly about their experience, albeit still with apprehension because other scholars might not sympathise with the ideas presented in their chapters:

I don't know the readership of this book, and some people reading this book might not be on the same page. I'm on that page and these other guys that think and work along the same lines as me, they're on that page, but we might get this book reviewed and someone might think completely different and might attack me for this.

The literature on gay men's studies was a crucial resource for many contributors, especially the literature that uses first-person accounts as a focal point because it encouraged authors to write about their own experience, which would give them a level of understanding of the vulnerability that comes when using personal experience as the main source to construct an argument. As one contributor put it:

I felt it was hypocritical of me to ask others in my professional life to do this type of self-disclosure work, but for me never to do it. I felt it was time to 'come out from behind the professional facade' to be more directly open and engaged in the work of research and what it means to be a gay man working in his field. For me, this literature gave me the permission, strength, and courage to do it. We all stand on the shoulders of others in this work, and my little chapter could not have been created hadn't it been for those other guys who had come before and had the courage to publish what they published and to say what they said. 

resources

For some contributors, everyday conversations and situations became a domain of analysis. These were conversations with themselves, with other specific people, dead or alive, or wider imaginary audiences. They used these conversations and situations as analytical tools to help them process the emotional aspects of the relationships about which they wrote. They gave information on how people interacted and the impact those interactions had on the contributor and how they see the world. As one contributor said: 'I engage in situations with different categories - sexual difference, masculinity, deep intimacy, vulnerability - core features of my work. I use other literature and theory to unpack these in the everyday'.

All the contributors used memories, dreams, and flashbacks as data. These embodied ways of knowing also included sources such as sensorial data - smells, flavours, tactile stimuli - and their association's responses to those. The difference in data sources spoke about how each contributor conceptualised data and their philosophical stance on what data is. One contributor used previous research interview transcripts as a source of material. He recalled moments that have stayed with him for ten or 15 years snippets of research data that his thoughts meandered too. Emotional points - a reaction - where he could stick a mental note. He used these as starting points of reflection. He reported:

'And it's really interesting to see what is revealed when you change the perspective from looking at the participants. I've built my research career by talking to others and trying to understand what others have to say. And what I am looking at this time is inside me'.

Using self as a source for the research generated a sense of alertness amongst contributors. It was a point of reflection about what constitutes data in research and how evidence is conceptualised in their respective disciplines. One author was concerned about the validity of quoting himself or using his own memory, because in the discipline he works in, the convention is that data is provided only by research participants' input. At first, it was difficult for him to locate himself as the researcher and as a source of the data. His dilemma speaks not only to him as an individual, but to the whole discipline of the natural sciences. How is knowledge constructed? Whose voices have validity? These and other questions emerged from the disciplines contributors worked in, and these concerns were not exclusive to the natural sciences. One contributor recalled how a friend of his, a literary academic who uses books and novels as sources of analysis writes about them all the time. He recalled:

[My friend] wrote an entire critique of 'Giovanni's Room' (Baldwin, 1990), which deals with gay characters, and he wrote it effortlessly, and I've read many other of his reviews on queer topics. But when I told him I was writing an autoethnography, he said he would struggle to write about his 
own experience. And he said: 'Why would I write about my own life?' There was something about the first-person experience that seems perplexing for him, but perhaps it's even something more fundamental, like he wasn't seeing his own experience as a valid source of data'.

\section{Audiences as sources for the writing}

Writing with an audience in mind was an important source for some contributors. We asked them: 'How do you think these imaginary audiences influenced your processes?'

Some authors expressed how writing with a particular reader in mind was helpful in finding their focus and developing their writing. For example, that other gay people who find themselves reflected in the narration might read their chapter was an important motivation to write. Imagining other people's responses to their writing also functioned as an 'ethical compass', which helped them imagine possible scenarios and make decisions on selfcare and confidentiality. For example, that people from certain professional bodies or academic organisations would read their chapters was a common concern amongst contributors. They negotiated this type of concern by referring to ethical principles of their own disciplines. A common way to resolve ethical tensions was by thinking of the potential positive impact that the writing would bring to people who are beneficiaries in their respective disciplines. As one author expressed:

If this text helps some people [in my academic discipline] see the need to develop more refined interventions for LGBTQ people, if someone says: 'oh, I hadn't thought about things this way, maybe I need to revisit my assumptions', then I'll feel that this was worth the risk.

However, having an audience in mind was not always a helpful occurrence. One writer described he had 'too many people in his head'. During the writing process, he kept thinking of former research participants, his research topic, and he tried to squeeze and stretch his story so it appealed to them all. He found the thought of others reading his personal story anxietyprovoking. At the stage of journaling for himself, the autoethnographic process felt good and appropriate, but when thinking that others were going to see his writing, he struggled. He dealt with the multiplicity of voices in his head by reducing his imagined audience by initially writing only for himself and for his partner. He found the writing a way of putting into words what he struggled to say to him in person.

Following the previous author's comments about a reduced audience, another contributor also found it difficult to write when there were many people in his mind. He explained that in his approach to autoethnography, if he pre-defines an audience for his text, he gets into a problem of blockage in his work that does not move him to write. Instead, he got into writing about the everyday by a recurrent conversation that he had or he wished he could have had with someone who is no longer here; these imagined 
conversations led him to engage in moments of everyday interactions that scarred him, marked him, or changed how he acted - and then he wrote about them. These thoughts generated some affective states that he then used as resources for his writing too. The thought that the person in his thoughts will never know certain aspects of his life elicited a profound sense of loss that was difficult to deal with. Both the affective states and this person as his primary audience served as a motivation for his piece, manoeuvring through everyday turbulence and longing.

In starting with an imaginary conversation, other contributors developed their chapters from 'writing small snippets of experience' before branching out into the wider cultural conversations associated with their topics. By asking 'What have other people said about these themes?' they identified concepts on which they later conducted further research. This strategy helped them to ask broader questions and incorporate these into autobiographical material before finishing their piece by returning to micro moments.

\section{Voice}

For many contributors, particularly those writing about mental distress, their writing was very personal, very difficult, and very raw. That meant, for some, playing with the voice in which they wrote the piece as a way to manage their emotions. One contributor spoke of using different voices as a way throughout various stages of the writing. Using different voices allowed him to take his text into different directions and to experience different feelings, which helped him to 'get into spaces' his other voices could not.

The option to use first-, second-, and third-person voices was an important resource to protect authors from the potential harm emerging from disclosing intimate parts of their lives. For some authors, writing their chapters in the first person from the start was too painful. As one of them said:

"Using "I" is the most difficult thing [...] using the second- or third-person voice throws the text onto the reader and off me [...] it allows me to share different things safely, [using the first-person voice] makes it too personal and can affect me more than I am prepared for'.

Some authors tried writing in the second- and third-person voice and others used the plural as well to take pressure from themselves and explore different affective responses. However, they also were conscious that as autoethnographers, switching voices was allowed, as long as the narration was still rooted in personal experience.

\section{Creating the conditions for the writing process}

Writing can be a mystified practice, as it is a personal and normally solitary experience. When discussing the actual writing process, something that can be an ordinary, everyday practice, some authors had to delve deep into their experience to clarify how they approach the task. 
As one contributor said: 'I fucking hate writing. I just need to write', which revealed an apparent straightforwardness of the process, as if they just need to 'do it'. In trying to unpack what happens in the writing process, we spoke with authors about the conditions that favour this activity. One of them, who has a background in music and is 'very music orientated', narrated how he uses playlists associated with his writing, and how he writes on an evening, after a few beers, which elicits a space that he associates with writing.

Another author describes an initial writing phase that is messy and confusing - 'a beautiful mess'. They wrote all their ideas in a blank document which was 'very rough' and helped them get significant content on the document. That document became 'a companion paper' to their main chapter. The concept of a companion paper was a messy, disorganised paper, with thoughts roughly laid out, and 'bullet point after bullet point' that is developed along the main chapter. The companion paper was made from pure and powerful personal content the contributor used as a reflective paper and from which they could either pull ideas or sections of text to incorporate into his main body of work or use them as a personal, reflective space. This was an approach that was used by at least one other contributor. $\mathrm{He}$ described how he works with multiple documents in which he puts a collection of thoughts and narratives. These narratives or seminal ideas felt powerful for him, but the meaning of them was still unknown.

The unknown or unprocessed quality of the contents in those companion papers was not concerning to the authors, as they used them as potential content for future writing, something that could mature and develop into something else.

\section{Entangled ideas and fragmented texts}

A sense of entanglement was a common occurrence in the authors' experience of writing their chapters. They described how the complexity of their lived experiences was reflected in their writing. The many angles to approach their narrations could mean that their writing could become confusing and their arguments could weaken.

For one contributor, 'too much reading' meant he went off on a tangent. He felt pulled from too many directions, which led to difficulty in structuring his work. He was feeling 'like headphone cables all tied up in knots and trying to untangle them'.

In trying to work out what the issue was, he reflected on the possibility that the entanglement could be part of the text that needed to be there. Maybe a sense of entanglement was what the chapter was about. This sense of an entangled text was experienced by other authors as well, so we invited them to leave their texts like that and share them with us to see how they worked. In reading their texts, part of our feedback as editors consisted in embracing the complexity and discussing with them that some texts benefit from not 
having a clear and linear narrative. We encouraged them to 'stay with' their texts and offer them as expressive texts that allow the reader to experience with them part of the affective states that impregnated the narrative.

When providing this feedback to one contributor, he commented:

This reminds me of the text, Ordinary Affects (Stewart, 2008), which brings tangled narratives that then leaves for readers to interpret and moves onto another. It's not linear, and in appearance, it does not have a narrative arch, but it does when you finish the book, or at least I made sense of it that way.

We reflected on how, perhaps, it was best to leave the entanglement there. For one author, that became an opportunity to think about using form in unique ways and reflect on his 'fragmented' writing, his sense of not knowing where he was going as the main offering. Perhaps, in some ways, that sense of not knowing where he was going was the story.

Other contributors embraced a sense of fragmentation in their work. One of them explained how a sense of apparent fragmentation makes sense once the author and the reader allow themselves to enter the text with freedom. He said:

In some work, using fragments or notes is the methodology. For example, Susan Sontag's wonderful work 'Notes on Camp' (1966). All she uses is 47 notes. That's the essay. There are no linear arguments, just 47 notes which are profound. Similarly, Peggy Macintosh, on white privilege (1989), she created lists of white privileges, not so much as content but as form to generate ideas.

One contributor likened his writing process to constructing a brick structure. Each brick was separate in that it represented an account, a tale, a reflection, or an extract from a research interview. But each brick was necessary to build the structure. There was no attempt at making sense. Each brick had to be read separately for you to get a sense of the experience.

These examples of fragmented and entangled ways of writing suggested a way to get us into writing spaces, to spark curiosity, and to engage in different ways to approach work. These conversations between editors and contributors became on some occasions an opportunity for peer mentoring. From one of these exchanges, two contributors used the genre of performative autoethnography to do their storytelling work. The performative aspect helped to invite a sense of seeing the scenes and being in conversation with the authors. They used the performative qualities of their work to evoke feelings in the readers to witness closely the experiences they were reminiscing through their writings - a co-sharing of feelings and experiences.

\section{Sharing their work in progress}

Each author had their own personal approach to sharing their work in progress. One contributor did not share early versions of his work; he shared only the abstract, as he wanted his text to be a surprise: 'like a movie trailer'. 
Others volunteered their work to be shared with other contributors to get an understanding of what others were doing and generate intertextuality. One contributor, however, did not want to see other contributions, as he did not want other people's writing to impact or influence his work at an early stage of its development.

In contrast, for another author, receiving feedback from us, Edgar and Jason, was an important part of their writing process. The editorial comments meant they could dive deeper into their exploration of ideas. Feedback helped them to 'flourish', and 'gave more life' to the writing. They said getting consistent feedback from us was crucial and emphasised the need not just to send one near-complete draft for comment but various versions before reaching the final chapter. For them, a steady flow of comments and responses helped them polish their piece.

For another contributor, seeing what others were writing allowed him 'to see how brave they have been and that allows me to be brave too'. Other contributors too spoke of feeling apprehensive about their work. They worried if their piece was a good fit for the book. They questioned the extent to which their piece spoke to the everyday and mundane and how much other gay men and academic readership would relate to their piece. For one this process was reminiscent of times when he has been part of special issues for different journals in which sharing work in progress has not been a common practice and, from the experience of collaborating in this book, he felt it is a beneficial practice for him to see what other people are working on.

\section{Final thoughts and advice for others}

When asked what advice they had for others writing autoethnography, authors reflected on their experiences of writing for this and other projects and shared the following.

One contributor reflected it is important to:

Let yourself go into the process; you learn as you do. Don't walk in knowing the scene. Ah, this is going to happen [...] stuff happens in writing. You don't know what you are going to say until you start saying it.

Another advised others to be reflective of themselves and the process:

Understand and feel your emotions as autoethnography can be an emotional process, write rough ideas in a notepad - because you can get a really good piece from a rush of ideas and save unused writing for another project.

Finally, another author reminded autoethnographers to practice self-care during the writing process when he said:

Be kind to yourself. Nothing is perfect, and sometimes it's the imperfections that give birth to a perfect piece. Be keenly aware of your emotions when writing and what that does to you. Autoethnography pieces can be emotionally driven, but sometimes you don't need to be so immersed. It's just a written piece and not what's happening right now in the moment. It's part of your everyday life, but it's not the emotion that's present every 
minute or every hour. Give yourself breath, give yourself space and time to recover from this piece.

Wise words, that as editors of this collection, we echoed.

\section{References}

Baldwin, J. 1990. Giovanni's room, London: Penguin.

Downs, A. 2006. The velvet rage: Overcoming the pain of growing up gay in a straight man's world, Cambridge, MA: Da Capo Press.

Ellis, C. 2007. Telling secrets, revealing lives: Relational ethics in research with intimate others. Qualitative Inquiry, 13, 3-29.

Frederick, B. J. 2014. "Delinquent boys": Toward a new understanding of "deviant" and transgressive behavior in gay men. Critical Criminology (Richmond, B.C.), 22, 139-149.

Gale, K. \& Wyatt, J. 2017. Working at the wonder: Collaborative writing as method of inquiry. Qualitative Inquiry, 23, 355-364.

Galvin, K. T. \& Prendergast, M. 2016. Poetic inquiry II - Seeing, caring, understanding: Using poetry as and for inquiry, Rotterdam: Brill.

Lorde, A. 1984. Sister outsider: Essays and speeches, Trumansburg, NY: Crossing Press.

Macintosh, P. 1989. White privilege: Unpacking the invisible knapsack, Wellesley, MA: Wellesley Centers for Women.

Prendergast, M., Leggo, C. D., Sameshima, P. \& Brill, E. J. 2009. Poetic inquiry: Vibrant voices in the social sciences, Rotterdam: Sense Publishers.

Richardson, L. \& St. Pierre, E. A. 2005. Writing: A method of inquiry. In J. Van Maanen (Ed.), The Sage handbook of qualitative research, 3rd ed. Thousand Oaks, CA: Sage Publications Ltd.

Sontag, S. 1966. Against interpretation: And other essays. New York: Farrar, Straus and Giroux.

St. Pierre, E. A. 2017. Writing post qualitative inquiry. Qualitative Inquiry, 24, 603-608.

Stewart, K. 2008. Ordinary affects, Durham, NC: Duke University Press.

Wyatt, J. 2019. Therapy, stand-up and the gesture of writing: Towards creativerelational inquiry, New York: Routledge. 